\title{
Botulinum toxin type-A preparations are not the same medications - basic science (Part 1)
}

\author{
Halina Car ${ }^{1}$, Andrzej Bogucki ${ }^{2}$, Marcin Bonikowski ${ }^{3}$, Małgorzata Dec-Ćwiek $^{4}$, Artur Drużdż ${ }^{5}$, \\ Dariusz Koziorowski ${ }^{6}$, Monika Rudzińska-Bar ${ }^{7}$, Iwona Sarzyńska-Długosz ${ }^{8}$, Jarosław Sławek ${ }^{9}$ \\ ${ }^{1}$ Department of Experimental Pharmacology, Medical University of Bialystok, Bialystok, Poland \\ ${ }^{2}$ Department of Extrapyramidal Disorders, Medical University of Lodz, Poland \\ ${ }^{3}$ Neuro Rehabilitation Department, Movement Analysis Lab., Mazovian Neuropsychiatry Centre, \\ Limited Liability Company, Zagorze, Poland \\ ${ }^{4}$ Department of Neurology, Collegium Medicum, Jagiellonian University, Krakow, Poland \\ ${ }^{5}$ Department of Neurology, Municipal Hospital in Poznan, Poland \\ ${ }^{6}$ Department of Neurology, Medical University of Warsaw, Warsaw, Poland \\ ${ }^{7}$ Department of Neurology, Faculty of Medicine and Health Sciences. Andrzej Frycz Modrzewski Krakow University, Krakow, Poland \\ ${ }^{8}$ Second Department of Neurology, Neurorehabilitation Ward, Institute of Psychiatry and Neurology, Warsaw, Poland \\ ${ }^{9}$ Division of Neurological and Psychiatric Nursing, Faculty of Health Sciences, Medical University of Gdansk, Poland; \\ Department of Neurology and Stroke, St. Adalbert Hospital, Gdansk, Poland
}

\begin{abstract}
Botulinum neurotoxin type- $\mathrm{A}$ (BoNT/A) formulations are widely used in clinical practice. Although they share a common mechanism of action resulting in presynaptic block in acetylocholine release, their structure and pharmacological properties demonstrate some similarities and many differences. Bioequivalence has been discussed since the onset of the clinical use of BoNT/A. In this review, we provide an update on the studies and compare the molecular structure, mechanisms of action, diffusion and spread, as well as immunogenicity and dose equivalence of onabotulinumtoxinA, abobotulinumtoxinA and incobotulinumtoxinA.

Key words: botulinum toxin $A$ formulation, pharmacological similarities and differencies, abobotulinumtoxinA, onabotulinumtoxinA, incobotulinumtoxinA
\end{abstract}

(Neurol Neurochir Pol 2021; 55 (2): 133-140)

\section{Introduction}

Botulinum toxins are 'natural products' of living bacteria of the genus Clostridium. Particular therapeutics of botulinum toxin, although based on the same serotype A formulations (BoNT/A), have distinct properties. The main three BoNT/A products commercially available worldwide today are derived from Clostridium botulinum Hall strain: onabotulinumtoxinA (ONA-BoNT/A) marketed as Botox/Vistabel by Allergan Inc. (Irvine, CA, USA); abobotulinumtoxinA (ABOBoNT/A) marketed as Dysport/Azzalure by Ipsen/Galderma (Paris, France); and incobotulinumtoxinA (INCO-BoNT/A) marketed as Xeomin/Bocouture by MerzPharmaceuticalGmbh (Frankfurt, Germany).

New BoNT/A formulations have recently been introduced to the market: prabotulinumtoxinA-xvfs (PRA-BoNT/A) marketed as Jeuveau/Nabota/Nuceiva by Evolus/Daewoong and daxibotulinum toxin A (DAXI-BoNT/A) (formerly RT002) by Revance. Additionally, letibotulinum toxinA (Croma/Hugel with Botulax) is in Phase III trials although results have not been published yet.

Botulinum neurotoxin type-A preparations use in clinical practice is based on presynaptic chemical denervation of cholinergic synapses due to the cleavage of specific synaptic

Address for correspondence: Jarosław Sławek, MD, PhD, Department of Neurology and Stroke, St. Adalbert Hospital, Al. Jana Pawła II 50 Str., 80 -462 Gdansk, Poland, e-mail: jaroslaw.slawek@gumed.edu.pl 
Table 1. Comparison of selected characteristics of botulinum toxin type-A preparations based on Frevert 2015 [3], Kutschenko et al. 2016 [42]*, Pirazzini et al. 2017 [11], Ferrari et al. 2018 [80], and Field et al. 2018 [81]**

\begin{tabular}{|c|c|c|c|}
\hline & Botox/Vistabel & Dysport/Azzalure & Xeomin/Bocouture \\
\hline Generic name/short name & $\begin{array}{l}\text { OnabotulinumtoxinA/ } \\
\text { /(ONA-BoNT/A) }\end{array}$ & $\begin{array}{l}\text { AbobotulinumtoxinA/ } \\
\text { /(ABO-BoNT/A) }\end{array}$ & $\begin{array}{l}\text { IncobotulinumtoxinA/ } \\
\text { /(INCO-BoNT/A) }\end{array}$ \\
\hline C. botulinum strain & Hall A-hyper & Hall A & Hall A (ATCC 3502) \\
\hline Toxin type & $\mathrm{A} 1$ & A1 & $\mathrm{A} 1$ \\
\hline Molecular Weight (MW) & $900 \mathrm{kDa}$ complex & Not reported & $150 \mathrm{kDa}$ \\
\hline Purification method & Crystallisation & Chromatography & Chromatography \\
\hline $\begin{array}{l}\text { Pharmaceutical form for recon- } \\
\text { stitution }\end{array}$ & Vacuum-dried powder & Freeze-dried powder & Freeze-dried powder \\
\hline Shelf life & $2-8^{\circ} \mathrm{C} / 36$ months & $2-8^{\circ} \mathrm{C} / 24$ months & Room temperature/36 months \\
\hline Storage after reconstitution & Up to $24 \mathrm{~h}$ at $2-8^{\circ} \mathrm{C}$ & Up to $8 \mathrm{~h}$ at $2-8^{\circ} \mathrm{C}$ & Up to $24 \mathrm{~h}$ at $2-8^{\circ} \mathrm{C}$ \\
\hline $\mathrm{pH}$ (reconstituted) & 7.4 & 7.4 & 7.4 \\
\hline Excipients in vial & $\begin{array}{l}100 \mathrm{U} \text { : human serum albumin } \\
0.5 \mathrm{mg}, \mathrm{NaCl} 0.9 \mathrm{mg}\end{array}$ & $\begin{array}{l}500 \mathrm{U} \text { : human serum albumin } \\
0.125 \mathrm{mg} \text {, lactose } 2.5 \mathrm{mg}\end{array}$ & $\begin{array}{l}100 \mathrm{U} \text { : human serum albumin } \\
1 \mathrm{mg} \text {, sucrose } 4.7 \mathrm{mg}\end{array}$ \\
\hline Unit/vial & $100 \mathrm{U}$ or $200 \mathrm{U}$ Botox/50 U Vistabel & $\begin{array}{l}300 \text { U or } 500 \text { U Dysport/ } \\
125 \text { U Azzalure }\end{array}$ & $\begin{array}{l}100 \mathrm{U} \text { or } 200 \mathrm{U} \text { Xeomin/ } \\
\text { /50 U Bocouture }\end{array}$ \\
\hline Protein load/vial & $5 \mathrm{ng} / 100 \mathrm{U}$ & $4.35 \mathrm{ng} / 500 \mathrm{U}$ & $0.44 \mathrm{ng} / 100 \mathrm{U}$ \\
\hline $\begin{array}{l}\text { Quantity of neurotoxin } \\
\text { (ng protein/100 U) }\end{array}$ & $\begin{array}{c}\sim 0.73 \mathrm{ng} / 100 \mathrm{U} \\
\sim 0.90 \mathrm{ng} / 100 \mathrm{U}^{* *}\end{array}$ & $\begin{array}{l}\sim 0.65 \mathrm{ng} / 100 \mathrm{U} \\
\sim 0.54 \mathrm{ng} / 100 \mathrm{U}^{* *}\end{array}$ & $\begin{array}{l}\sim 0.44 \mathrm{ng} / 100 \mathrm{U} \\
\sim 0.40 \mathrm{ng} / 100 \mathrm{U}^{* *}\end{array}$ \\
\hline $\begin{array}{l}\text { Specific potency of } 150 \mathrm{kD} \text { BoNTA } \\
\text { neurotoxin }\end{array}$ & 137 units/ng & 154 units/ng & 227 units/ng \\
\hline $\begin{array}{l}\text { Wheel-running performance of } \\
\text { mice study activity in relation to } \\
\text { ONA-BoNTA* }\end{array}$ & 1 & 2.0 & $1.3-2.0$ \\
\hline Unit testing & $\begin{array}{l}\text { Cell-based potency assay specific } \\
\text { to Allergan BoNT/A product }\end{array}$ & $\begin{array}{l}\mathrm{LD}_{50} \text { assay specific to Ipsen BoNT/A } \\
\text { product }\end{array}$ & $\begin{array}{c}\mathrm{LD}_{50} \text { assay specific to Merz BoNT/A } \\
\text { product }\end{array}$ \\
\hline
\end{tabular}

proteins. This results in a decrease of acetylocholine release. Despite the common mechanism, these preparations are distinct medications, with many differences in terms of their structure, potency and immunogenicity. These differences may result in differing clinical efficacy and safety as well as pharmacoeconomic profiles, and have been discussed in medical literature over many years.

The aim of this paper was to show pharmacological similarities among, and differences between, the three most widely used BoNT/A preparations: ONA-, ABO-, and INCO-BoNT/A.

\section{Structure}

ONA-BoNT/A and ABO-BoNT/A are purified neurotoxin complexes including the BoNT/A1 and BoNT/A2 toxin molecules, respectively, and neurotoxin accessory proteins: NAPs - three haemagglutinin (HA) proteins and one non-toxic non-HA protein. It has been suggested that non-toxic HA not only stabilises the biological activity of the product in vivo, but also enables HA-botulinum toxin complex to adhere to muscle tissue [1]. INCO-BoNT/A contains only purified BoNT/A1 [2-4]. Results from a few studies have shown that $\sim 150 \mathrm{kDa}$ BoNT/A protein is mostly linked with NAPs [5,
6] at physiological $\mathrm{pH}$ levels, but other studies have suggested that prior to or shortly after injection the NAPs dissociate from botulinum toxin $[7,8]$. Another study concluded that ONA-BoNT/A and ABO-BoNT do not contain neurotoxins in complexed form [8]. All commercial products contain an excipient, known as human serum albumin (HSA), which improves toxin stability and diminishes toxin loss during lyophilisation, prevents protein aggregation and surface adsorption, as well as extends shelf life [4].

ONA-BoNT/A is vacuum dried, while $\mathrm{ABO}-\mathrm{BoNT} / \mathrm{A}$ and INCO-BoNT/A are freeze dried. All formulations before clinical use are reconstituted with sterile normal saline buffer, yielding a solution that is slightly acidic $[9,10]$. The reconstitution processes of ONA-BoNT/A results in a complete dissociation of $900 \mathrm{kDa}$ complexes and the release of more than $85 \%$ of neurotoxins in free form [8].

A comparison of selected characteristics of BoNT/A preparations is set out in Table 1.

\section{Mechanism of action}

The activity of the botulinum toxin known as 'chemical denervation' refers to the decrease of the pre-synaptic release of acetylcholine, and temporary muscle paresis or inhibition 
of glandular secretion. Additionally, BoNT/A inhibits the release of other neurotransmitters and influences inflammatory cells. This is probably the basis of its antinociceptive activity [11].

The mechanism of action of botulinum toxin A includes: 1. binding to nerve terminals; 2 . internalisation within an endocytic compartment; 3 . translocation into the cytosol; 4. the cleavage of SNARE complex by $L$ chain; and 5 . reduction of acetylcholine release from the pre-synaptic terminal.

1. In detail, according to 1., the $\mathrm{C}$-terminal heavy chain $(\mathrm{H})$ contains a translocation domain (HN) and a receptor binding domain (HC). The $\mathrm{HC}$ includes an $\mathrm{N}$-terminal subdomain (HCN) of unspecified function and a C-terminal subdomain (HCC) that selectively bonds to dual neuron-specific receptors - ganglioside GT1b, and the protein receptor SV2C on the presynaptic plasma membrane in particular neurons $[12,13]$. BoNT serotype A1 and A2 binds to the glycosylated SV2C receptor synaptic vesicle glycoprotein 2C (SV2C) [13], which allows for rapid penetration of toxins, at similar rates, via the same synaptic vesicles. HCA2 has higher affinity for receptor and neurons than HCA1 [14]. Glycosylation Asn559 in SV2C is critical for binding of BoNT/A to presynaptic plasma membrane. Glycosylation patterns in this site vary among adult individuals [15]. Pirazzini et al. have suggested that this feature may be responsible for a different onset and duration of induced neuroparalysis in humans following administration of the same dose of BoNT/A1; probably, different amounts of bound toxin are likely to match different numbers of $\mathrm{L}$ chains entering the cytosol in nerve terminal [11].

2. The toxin enters the synaptic vesicles of motor axon terminals by endocytosis. Internalisation of BoNT/A is mediated by receptor of a polysialoganglioside (PSG), the glycosylated luminal domain of a synaptic vesicle protein and unique $\mathrm{N}$-glycans attached to synaptic vesicle (SV) glycoproteins [16], as well as to E-cadherin [17-19], fibroblast growth factor and vanilloid receptors $[20,21]$. The increased endocytosis rate of BoNT/A and a frequent exposure of the SV lumen was observed during stimulation of nerves. It has been demonstrated [18] that nontoxic HA protein (present in ONA- and ABO-BoNT/A) sequesters E-cadherin in the monomeric state, disrupts the intercellular epithelial barrier, and facilitates paracellular absorption of BoNT/A [20, 22].

3. The $\mathrm{L}$ chain $(\mathrm{L})$ of toxin is translocated across the vesicle membrane into the cytosol. Acidification of the synaptic vesicle lumen triggers $\mathrm{HN}$ to form a channel to $\mathrm{L}$ translocation. Next, the $\mathrm{L}$ chain is released from $\mathrm{H}$ chain by reduction of the interchain disulfide bond.

4. Next, $\mathrm{L}$ chain cleaving the soluble $\mathrm{N}$-ethylmaleimide-sensitive factor attachment protein receptors (SNAREs), particularly synaptosomal associated protein of $25 \mathrm{kDa}$, SNAP-25.
5. Finally, SNAP-25 prevents the docking and exocytosis of acetylcholine from pre-synaptic vesicles at neurosecretory and neuromuscular junctions. Detailed mechanism of nerve paresis by BoNT/A is described in a review by Pirazzini et al. [11]. The study by Grando and Zachary [23] presented the non-neuronal and non-muscular mechanisms and effects of BoNT/A in many normal and cancer cell lines. Differentially altered genes expression by BoNT/A involved in signal transduction, immunity and defence, protein metabolism and modification, neuronal activities, intracellular protein trafficking and muscle contraction [24] show the huge range of mechanisms and possible effects of botulinum toxin. For example, ONA-BoNT/A injection markedly reduced, by $53 \%$, urothelial ATP release in patients with spinal cord injury [25], increased nitric oxide (NO) release from the urothelium in the bladder detrusor [26], decreased expression of purinergic receptors (P2X3) in the bladder mucosa [27], inhibited the evoked release of CGRP from afferent nerve terminals in the bladder reducing pain [28], reduced bladder inflammation by decreasing urothelial apoptosis and the expression of vascular endothelial growth factor in the bladders of patients with interstitial cystitis (IC)/bladder pain syndrome (BPS) [29]. Recent studies have revealed that BoNT/A has antinociceptive peripheral effects by blocking synaptic transmission of glutamate, dopamine, ATP and gamma-aminobutyric acid regulation and serotonin [30].

The results of analysis of over 40,000 BoNT/A treatment reports indicate that patients who received BoNT/A in a broad range of injection sites had a significantly lower number of depression reports compared to patients undergoing different treatments for the same conditions [31]. Such results have allowed for the introduction of ONA-BoNT/A in Phase III studies designed so as to obtain FDA indication for major depression [32, 33].

The main mechanism of the ability of BoNT/A to weaken hyperactive secretory cells and relax tense muscles is the same for currently registered preparations, while the detailed additional effects mentioned above are described for ONA-BoNT/A only.

\section{Diffusion and spread out}

Distant effects of BoNT/A formulations may be the result of haematogenous spread defined as migration in local and regional muscles [34,35], or as distant migration in areas non-contiguous with the injection [36-39]. Diffusion is characterised as microscopic movement of a soluble molecule's dispersion by passive transport to local and distant tissues [40] away from the intended area to nearby anatomical structures. The local spread of all BoNT/A formulations after injection depends on dilution, needle size, dose and volume, as well as injection technique [41]. Kutschenko et al. [42] suggested that the volume of injection is one of the major factors influencing the degree of muscle paralysis. The volume-dependent 
reduction of paresis in a wheel-running test was observed in mice injected with INCO-BoNT/A. Kutschenko et al. suggested that larger volumes induce more intense paresis [42]. Pirazzini et al. suggested that the amount of toxin needed for a certain application should be diluted according to the size of the muscle/area [11]. Based on this data, it may be considered that the diffusion of BoNT/A from the injection site is increased by its gradual dilution in increasing volumes of extracellular fluids thus diminished binding to the presynaptic membrane. Additionally, different degrees of paresis after ONA-BoNT/A, ABO-BoNT/A and INCO-BoNT/A were presented after injecting identical volumes $(10 \mu \mathrm{L})$ containing the same number of mouse units of BoNT/A into both hind leg muscles. Based on this experiment, the conversion ratio of INCO-BoNT/A and ONA-BoNT/A was estimated as being between 1:0.75 and 1:0.5. ONA-BoNT/A has shown a two-fold greater potency than $\mathrm{ABO}-\mathrm{BoNT} / \mathrm{A}$ [42].

Aoki et al. [36] proposed that protein complex size and pharmacological properties influence the diffusion of BoNT/A. That study showed that high-molecular-weight toxin complex of ONA-BoNT/A limits tissue distribution compared to ABO-BoNT/A [36]. More recent studies in which the size of anhidrotic halos was measured have shown different results. A comparison of ONA-BoNT/A and ABO-BoNT/A (using dose ratios of 1:2.5, 1:3, and 1:4, and identical injection volumes) presented a larger area of anhidrosis after $\mathrm{ABO}$ -BoNT/A [43]. Kerscher et al. obtained different mean maximal areas of the forehead anhidrosis of patients at 6 weeks after injection of BoNT/A formulations: comparable spread to ONA-BoNT/A and INCO-BoNT/A, and significantly greater to $\mathrm{ABO}-\mathrm{BoNT} / \mathrm{A}$ [44]. In another study, no significant differences between the mean size of halos produced by ONA-BoNT/A and ABO-BoNT/A were observed [45]. Similarly, no differences in diffusion of ONA-BoNT/A and INCO-BoNT/A injected to forehead at the same dose and using the same technique were demonstrated after 6 weeks and 6 months [46]. In other study, similar, limited to a distance of 30-45 mm [41], diffusion from the site of injection has been well documented by $\mathrm{N}-\mathrm{CAM}$ staining and characterised ONA-BoNT/A, INCO-BoNT/A and ABO-BoNT/A when they were used in a ratio of 1: $1: 4$ and in the same toxin injection volume $(25 \mu \mathrm{L})$ [47].

Results from the study by Brodsky et al. showed that the presence of complexing proteins in ONA-BoNT/A and ABO-BoNT/A does not reduce migration of the neurotoxin [48]. The diffusion for all formulations of BoNT/A is similar in the majority of studies, but the dose and volume of injection may be the most important factors in differentiating diffusion efficiency.

The retrograde axonal transport of BoNT/A to spinal motor neurons, followed by anterograde transport to the other motor units, has also been suggested [49]. Caleo et al. [50] showed that BoNT/A physically leaves the motoneurons to enter second-order neurons. After injection of ONA- BoNT/A into the nasolabial musculature of rats and mice, catalytically active ONA-BoNT/A was transported to the facial nucleus. The authors suggested that these findings highlight cell-specific, direct central actions of BoNT/A, which are important to fully understand its mechanisms of action and therapeutic effectiveness in movement disorders and pain treatment.

A few studies have shown that BoNT/A, injected intramuscularly, is transported both anterogradely along sensory axons and retrogradely by central neurons and motoneurons axons to the motoneuron soma in the spinal cord [51-54]. Autophagosomes undergo dynein-dependent retrograde axonal transport to the neuronal soma [55]. Moreover, Antonucci et al. observed SNAP-25 cleavage in the contralateral hemisphere after unilateral BoNT/A delivery to the hippocampus [51]. Harper et al. and Restani et al. showed that BoNT/A-HC is internalised in synaptic vesicles and undergoes retrograde trafficking [56, 57]. The retrograde axonal transport and transcytosis to second-order nociceptive neurons explains mechanisms of action of ONA-BoNT/A in migraine [58]. ONA-BoNT/A is the only one approved for the treatment of chronic migraine. Selected papers have presented retrograde transport for ONA-BoNT/A only.

According to the Simpson et al. study, botulinum toxin accesses the perineuronal fluid compartment and does not cross the blood-brain barrier [59]. These authors suggested that BoNT/A is a large molecule and it is not able to cross the blood-brain barrier.

\section{Immunogenicity}

Antibody formation against the accessory proteins was observed in patients after injection of BoNT/A formulation with associated proteins, but they did not interfere with the biological activity of the toxin ('non-neutralising') [60]. Results from a preclinical study suggest that the NAPs may physically secure neurotoxin against the immune system and finally against the formation of toxin-neutralising antibodies interfering with clinical response [61]. However, antibodies formed against the heavy chain may or may not prevent its biological activity. The immunological response of humans to BoNT/A is very low, ranging from $0 \%$ to $3 \%: 0 \%$ was reported for ONA-BoNT/A $[62,63]$ and for ABO-BoNT/A used in glabellar lines [63], 1.2\% for ONA-BoNT/A [62, 63], less than $3 \%$ for ABO-BoNT/A in cervical dystonia [63], and $1.1 \%$ for INCO-BoNT/A in upper limb spasticity. Each patient injected with INCO-BoNT/A was previously treated with a botulinum toxin A product which contained complexing proteins $[7,64]$. A comprehensive meta-analysis of 61 studies by Fabbri et al. [65] analysed the frequency of antibodies among $8,525 \mathrm{pa}$ tients receiving all registered types of BoNT/A across several clinical indications. Generally, the prevalence of antibodies among clinically responding patients was lower (3.5\%) than in secondary nonresponse patients (53.5\%). The frequencies of antibody formation independent of clinical responsiveness 
to BoNT/A formulations across all analysed clinical indications were $1.5 \%$ for ONA-BoNT/A, $1.7 \%$ for ABO-BoNT/A, and $0.5 \%$ for INCO-BoNT/A. The results of this analysis indicate the lowest frequency of antibody formation after INCO-BoNT/A. The prospective, single-arm, dose-titration TOWER study showed that no patient with spasticity with a cerebral cause developed secondary nonresponse due to neutralising antibodies after administration of INCO-BoNT/A in a range of doses between $400 \mathrm{j}$ and $800 \mathrm{j}$ [66].

Based on the results of the aforementioned studies, the presence of complexing proteins in BoNT/A formulations may increase the risk of the formation of neutralising antibodies.

The immunogenicity of the BoNT/A formulations depends on some factors that differ in the manufacturing process, mainly the source of toxin and the antigenic protein load and the presence of inactive or denatured toxin acting as a toxoid. Treatment-related factors such as the toxin dose, frequency of injections, as well as prior exposure via other routes (intradermal or distant to the target muscle), different formulations (e.g. first application of ONA-BoNT/A or ABO-BoNT/A and second of INCO-BoNT/A) and site of anatomical region (especially near lymph nodes) seem to play a role in the immunogenic response. Based on this knowledge, clinical practice suggests the use of the lowest effective doses and to maintain 12 weeks of minimal interval treatment [67]. On the other hand, shorter, less than half as long, intervals of injection of INCO-BoNT/A have been described as well tolerated and free of antibodies [68].

\section{Doses}

A dose equivalence of BoNT/A formulations is still being discussed. The potency of BoNT/A preparations is expressed as Units $(\mathrm{U})$ and $1 \mathrm{U}$ corresponds to one LD50 in mouse bioassay $[69,70]$. Different diluents for LD50 testing have used by manufacturers: Allergan uses saline [71]; Ipsen uses gelatin phosphate buffer [72]; human serum albumin as a stabiliser was added by Merz to undisclosed diluent [73]. However, it has been suggested that stabilisers can enhance the activity of BoNT/A products at low concentrations in preclinical tests [74]. It is suggested that the diluent buffer significantly influences biological activity of BoNT/A products. Nonparallel doseresponse curves of ONA-BoNT/A and ABO-BoNT/A with different relative potencies can explain a dose conversion ratio between Botox and Dysport of 1:2.5-3 [74, 76] or 1:2 [43].

There are no internationally accepted standardised tests for BoNT/A product comparisons. For this reason, different assay methods with different proprietary product-specific reference standards for testing potency units are used. The clinical effect of one unit is not interchangeable between formulations due to differences in the bioassay methodologies used by producers [77]. The clinical literature has reported an equivalent potency between ONA-BoNT/A and INCO-BoNT/A [3], but this was not the case in an animal (mouse) study [42]. The potency of INCO-BoNT/A and ONA-BoNT/A in inducing hind limb paresis in the wheel-running performance test in mice showed a conversion rate of between 1: 0.75 and 1: 0.5 [42]. The Allergan LD50 assay used ONA-BoNT/A and INCO-BoNT/A diluted in normal saline [72] to compare their activity. The obtained results showed that one INCO-BoNT/A vial contained less than 100 Allergan units (i.e. 69-78 units for three different lots) and clearly suggested the non-interchangeability of units in the studied products. Additionally, these results were confirmed in an enzymatic cleavage assay, the Digit Abduction Score assay, as well as replication of the LD50 results [78, 79]. Dressler et al. [73] indicated that assay conditions markedly influence potency measurements. Moreover, dose-response data of BoNT/A formulations is used to determine the therapeutic dose range as the 'benefit-risk' rate from acceptable efficacy and safety profiles. Significantly different muscle weakening efficacies identified as 50\% maximal (median effective dose -ED50) have been reported for the three main BoNT/A products, and furthermore not equipotent units of the botulinum toxin formulations that are under experimental conditions were presented $[36,79]$.

Additionally, different quantities of $150 \mathrm{kDa}$ (ng protein/100 U) of BoNT/A in formulation (the lowest in INCOBoNT/A and the highest in ONA-BoNT/A) were shown by Ferrari et al. [80] and Field et al. [81] (see also Table 1). Calculated analysis shows differences between BoNT/A formulations. The highest amount of neurotoxin per product unit (in pg) and the total amount of active BoNT-A (in ng) injected at the recommended dose for an adult lower limb and an adult upper limb were obtained for ABO-BoNT/A. However, the relative quantity of $\mathrm{rBoNT} / \mathrm{A}$ assessed as a ratio quantity obtained by the EndoPep method to protein quantity tested by ELISA method demonstrated not significant differences in LC activity-tested BoNT/A formulations. This indicates that the $150 \mathrm{kDa}$ neurotoxin molecules in each product are equally active [81].

Some studies have shown the non-interchangeability of units of ONA-BoNT/A and INCO-BoNT/A. The highest total amount of active BoNT/A being found after injection of ABOBoNT/A to lower and upper limbs may suggest a focus on the conversion rate between ONA-BoNT/A and $\mathrm{ABO}-\mathrm{BoNT} / \mathrm{A}$ or INCO-BoNT/A and ABO-BoNT/A.

\section{Summary}

The major difference in structure between BoNT/A formulations concerns the presence or absence of complexing proteins. The effectiveness of BoNT/A preparations is not dependent on complexing proteins, but they may increase the risk of the formation of neutralising antibodies. The mechanism of action of all BoNT/A is similar, but the central effects of ONABoNT/A may expand indications for its use in major depression. Diffusion and spread out for all formulations of BoNT/A is similar in most studies. The retrograde axonal transport and transcytosis to second-order nociceptive neurons described for 
ONA-BoNT/A only justifies its usefulness in the treatment of chronic migraine. The non-interchangeability of units of ONABoNT/A and INCO-BoNT/A was shown in an animal study, and the highest total amount of active BoNT/A after ABOBoNT/A injection to lower and upper limbs may suggest the need for additional studies in other indications to confirm the correct conversion rate doses between BoNT/A preparations.

Based on the differences in biological assays and the variations of biological activity $[82,83]$, regulatory agencies in most countries worldwide require a statement of unit noninterchangeability among BoNT/A products.

\section{References}

1. Johnson EA, Bradshaw M. Clostridium botulinum and its neurotoxins: a metabolic and cellular perspective. Toxicon. 2001; 39(11): 1703-1722, doi: 10.1016/s0041-0101(01)00157-x, indexed in Pubmed: 11595633.

2. Frevert J. Xeomin: an innovative new botulinum toxin type A. Eur J Neurol. 2009; 16 Suppl 2: 11-13, doi: 10.1111/j.1468-1331.2009.02879.x, indexed in Pubmed: 20002741.

3. Frevert J. Pharmaceutical, biological, and clinical properties of botulinum neurotoxin type A products. Drugs R D. 2015; 15(1): 1-9, doi: 10.1007/s40268-014-0077-1, indexed in Pubmed: 25559581.

4. Pickett A. Botulinum Toxin as a Clinical Product: Manufacture and Pharmacology. Clinical Applications of Botulinum Neurotoxin. 2014: 7-49, doi: 10.1007/978-1-4939-0261-3_2.

5. Wagman J, Bateman JB. Botulinum type A toxin: properties of a toxic dissociation product. Arch Biochem Biophys. 1953; 45(2): 375-383, doi: 10.1016/s0003-9861(53)80014-7, indexed in Pubmed: 13081146.

6. Cai S, Sarkar HK, Singh BR. Enhancement of the endopeptidase activity of botulinum neurotoxin by its associated proteins and dithiothreitol. Biochemistry. 1999; 38(21): 6903-6910, doi: 10.1021/ bi990086c, indexed in Pubmed: 10346912.

7. Frevert J, Dressler D. Complexing proteins in botulinum toxin type A drugs: a help or a hindrance? Biologics. 2010; 4: 325-332, doi: 10.2147/BTT.S14902, indexed in Pubmed: 21209727.

8. Eisele KH, Fink K, Vey M, et al. Studies on the dissociation of botulinum neurotoxin type A complexes. Toxicon. 2011; 57(4): 555565, doi: 10.1016/j.toxicon.2010.12.019, indexed in Pubmed: 21195107.

9. Frevert J. Content of botulinum neurotoxin in Botox $\circledast /$ Vistabel $\circledast$, Dysport $₫ /$ Azzalure $\AA$, and Xeomin $₫ /$ Bocouture ${ }^{\circledR}$. Drugs R D. 2010; 10(2): 67-73, doi: 10.2165/11584780-000000000-00000, indexed in Pubmed: 20698714.

10. Dressler D, Adib Saberi F, Bigalke H. Botulinum toxin therapy: reduction of injection site pain by $\mathrm{pH}$ normalisation. J Neural Transm (Vienna). 2016; 123(5): 527-531, doi: 10.1007/s00702-0161522-9, indexed in Pubmed: 27002815.

11. Pirazzini M, Rossetto 0 , Eleopra R, et al. Botulinum Neurotoxins: Biology, Pharmacology, and Toxicology. Pharmacol Rev. 2017; 69(2): 200-235, doi: 10.1124/pr.116.012658, indexed in Pubmed: 28356439.

12. Jhang JF, Kuo HC. Botulinum Toxin A and Lower Urinary Tract Dysfunction: Pathophysiology and Mechanisms of Action. Toxins (Basel). 2016; 8(4): 120, doi: 10.3390/toxins 8040120 , indexed in Pubmed: 27110822.
13. Mahrhold S, Bergström T, Stern D, et al. Only the complex N559-glycan in the synaptic vesicle glycoprotein $2 \mathrm{C}$ mediates high affinity binding to botulinum neurotoxin serotype A1. Biochem J. 2016; 473(17): 2645-2654, doi: 10.1042/BCJ20160439, indexed in Pubmed: 27313224.

14. Lacy DB, Tepp W, Cohen AC, et al. Crystal structure of botulinum neurotoxin type A and implications for toxicity. Nat Struct Biol. 1998; 5(10): 898-902, doi: 10.1038/2338, indexed in Pubmed: 9783750.

15. Lauc G, Pezer M, Rudan I, et al. Mechanisms of disease: The human N-glycome. Biochim Biophys Acta. 2016; 1860(8): 1574-1582, doi: 10.1016/j.bbagen.2015.10.016, indexed in Pubmed: 26500099.

16. Kroken AR, Blum FC, Zuverink M, et al. Entry of Botulinum Neurotoxin Subtypes A1 and A2 into Neurons. Infect Immun. 2017; 85(1), doi: 10.1128/IAI.00795-16, indexed in Pubmed: 27795365.

17. Kammerer RA, Benoit RM. Botulinum neurotoxins: new questions arising from structural biology. Trends Biochem Sci. 2014; 39(11): 517-526, doi: 10.1016/j.tibs.2014.08.009, indexed in Pubmed: 25282537.

18. Sugawara Yo, Matsumura T, Takegahara Y, et al. Botulinum hemagglutinin disrupts the intercellular epithelial barrier by directly binding E-cadherin. J Cell Biol. 2010; 189(4): 691-700, doi: 10.1083/ jcb.200910119, indexed in Pubmed: 20457762.

19. Lee K, Zhong X, Gu S, et al. Molecular basis for disruption of E-cadherin adhesion by botulinum neurotoxin A complex. Science. 2014; 344(6190): 1405-1410, doi: 10.1126/science.1253823, indexed in Pubmed: 24948737.

20. Jacky BPS, Garay PE, Dupuy J, et al. Identification of fibroblast growth factor receptor 3 (FGFR3) as a protein receptor for botulinum neurotoxin serotype A (BoNT/A). PLoS Pathog. 2013; 9(5): e1003369, doi: 10.1371/journal.ppat.1003369, indexed in Pubmed: 23696738.

21. Li X, Coffield JA. Structural and Functional Interactions between Transient Receptor Potential Vanilloid Subfamily 1 and Botulinum Neurotoxin Serotype A. PLoS One. 2016; 11(1): e0143024, doi: 10.1371/ journal.pone.0143024, indexed in Pubmed: 26745805.

22. Sugawara Y, Yutani M, Amatsu S, et al. Functional dissection of the Clostridium botulinum type $B$ hemagglutinin complex: identification of the carbohydrate and E-cadherin binding sites. PLoS One. 2014; 9(10): e111170, doi: 10.1371/journal.pone.0111170, indexed in Pubmed: 25340348.

23. Grando SA, Zachary CB. The non-neuronal and nonmuscular effects of botulinum toxin: an opportunity for a deadly molecule to treat disease in the skin and beyond. Br J Dermatol. 2018; 178(5): 1011-1019, doi: 10.1111/bjd.16080, indexed in Pubmed: 29086923.

24. Kim YJ, Kim JH, Lee KJ, et al. Botulinum neurotoxin type A induces TLR2-mediated inflammatory responses in macrophages. PLoS One. 2015; 10(4): e0120840, doi: 10.1371/journal.pone.0120840, indexed in Pubmed: 25853816.

25. Khera M, Somogyi GT, Kiss S, et al. Botulinum toxin A inhibits ATP release from bladder urothelium after chronic spinal cord injury. Neurochem Int. 2004; 45(7): 987-993, doi: 10.1016/j.neuint.2004.06.001, indexed in Pubmed: 15337297.

26. Collins VM, Daly DM, Liaskos M, et al. OnabotulinumtoxinA significantly attenuates bladder afferent nerve firing and inhibits ATP release from the urothelium. BJU Int. 2013; 112(7): 1018-1026, doi: 10.1111/bju.12266, indexed in Pubmed: 23937318.

27. Apostolidis A, Popat R, Yiangou $Y$, et al. Decreased sensory receptors P2X3 and TRPV1 in suburothelial nerve fibers following intradetrusor injections of botulinum toxin for human detrusor 
overactivity. J Urol. 2005; 174(3): 977-82; discussion 982, doi: 10.1097/01.ju.0000169481.42259.54, indexed in Pubmed: 16094018.

28. Rapp DE, Turk KW, Bales GT, et al. Botulinum toxin type a inhibits calcitonin gene-related peptide release from isolated rat bladder. J Urol. 2006; 175(3 Pt 1): 1138-1142, doi: 10.1016/S00225347(05)00322-8, indexed in Pubmed: 16469640.

29. Peng $\mathrm{CH}$, Jhang JF, Shie JH, et al. Down regulation of vascular endothelial growth factor is associated with decreased inflammation after intravesical OnabotulinumtoxinA injections combined with hydrodistention for patients with interstitial cystitis-clinical results and immunohistochemistry analysis. Urology. 2013; 82(6): 1452.e1-1452. e6, doi: 10.1016/j.urology.2013.09.003, indexed in Pubmed: 24295265.

30. Akaike N. Shin MC Wakita M Torii Y Harakawa T Ginnaga A Kato K Kaji R Kozaki S. Trans synaptic inhibition of spinal transmission by A2 botulinum toxin. J Physiol. 2013; 15: 1031-1043, doi: 10.1113/ jphysiol.2012.242131. indexed in Pubmed 23109108.

31. Makunts T, Wollmer MA, Abagyan R. Postmarketing safety surveillance data reveals antidepressant effects of botulinum toxin across various indications and injection sites. Sci Rep. 2020; 10(1): 12851, doi: 10.1038/s41598-020-69773-7, indexed in Pubmed: 32732918.

32. Zamanian A, Ghanbari Jolfaei A, Mehran G, et al. Efficacy of Botox versus Placebo for Treatment of Patients with Major Depression. Iran J Public Health. 2017; 46(7): 982-984, indexed in Pubmed: 28845410.

33. Brin MF, Durgam S, Lum A, et al. OnabotulinumtoxinA for the treatment of major depressive disorder: a phase 2 randomized, double-blind, placebo-controlled trial in adult females. Int Clin Psychopharmacol. 2020; 35(1): 19-28, doi: 10.1097/YIC.0000000000000290, indexed in Pubmed: 31609787.

34. Cliff SH, Judodihardjo H, Eltringham E. Different formulations of botulinum toxin type $A$ have different migration characteristics: a double-blind, randomized study. J Cosmet Dermatol. 2008; 7(1): 50-54, doi: 10.1111/j.1473-2165.2008.00361.x, indexed in Pubmed: 18254812.

35. Pickett A, Dodd S, Rzany B. Confusion about diffusion and the art of misinterpreting data when comparing different botulinum toxins used in aesthetic applications. J Cosmet Laser Ther. 2008; 10(3): 181183, doi: 10.1080/14764170802094282, indexed in Pubmed: 18608706.

36. Aoki KR, Ranoux D, Wissel J. Using translational medicine to understand clinical differences between botulinum toxin formulations. Eur J Neurol. 2006; 13 Suppl 4: 10-19, doi: 10.1111/j.1468-1331.2006.01649.x, indexed in Pubmed: 17112345.

37. Dysport $\circledast$ (abobotulinumtoxinA) [prescribing information]. Boulogne-Billancourt: IpsenBiopharm Ltd; 2012. Accessed October. ; 8: 2020.

38. Coté TR, Mohan AK, Polder JA, et al. Botulinum toxin type A injections: adverse events reported to the US Food and Drug Administration in therapeutic and cosmetic cases. J Am Acad Dermatol. 2005; 53(3): 407-415, doi: 10.1016/j.jaad.2005.06.011, indexed in Pubmed: 16112345.

39. Food and Drug Administration. Letter Re: Docket No FDA-2008-P-0061. April 30, 2009. Silver Spring, MD: US Food and Drug Administration; 2009. Available at: http://www.fda.gov/downloads/Drugs/ DrugSafety/PostmarketDrugSafetyInformationforPatientsandProviders/DrugSafetyInformationforHeathcareProfessionals/UCM143989. pdf. Accessed October 8, 2020.
40. Ramirez-Castaneda J, Jankovic J, Comella C, et al. Diffusion, spread, and migration of botulinum toxin. Mov Disord. 2013; 28(13): 17751783, doi: 10.1002/mds.25582, indexed in Pubmed: 23868503.

41. Yiannakopoulou E. Serious and long-term adverse events associated with the therapeutic and cosmetic use of botulinum toxin. Pharmacology. 2015; 95(1-2): 65-69, doi: 10.1159/000370245, indexed in Pubmed: 25613637.

42. Kutschenko A, Manig A, Reinert MC, et al. In-vivo comparison of the neurotoxic potencies of incobotulinumtoxinA, onabotulinumtoxinA, and abobotulinumtoxinA. Neurosci Lett. 2016; 627: 216-221, doi: 10.1016/j.neulet.2016.06.001, indexed in Pubmed: 27268041.

43. Trindade de Almeida AR, Marques E, de Almeida J, et al. Pilot study comparing the diffusion of two formulations of botulinum toxin type A in patients with forehead hyperhidrosis. Dermatol Surg. 2007; 33(1 Spec No.): S37-S43, doi: 10.1111/j.1524-4725.2006.32330.x, indexed in Pubmed: 17241413.

44. Kerscher M, Roll S, Becker A, et al. Comparison of the spread of three botulinum toxin type A preparations. Arch Dermatol Res. 2012; 304(2): 155-161, doi: 10.1007/s00403-011-1179-z, indexed in Pubmed: 22002325.

45. Hexsel D, Dal'Forno T, Hexsel C, et al. A randomized pilot study comparing the action halos of two commercial preparations of botulinum toxin type A. Dermatol Surg. 2008; 34(1): 52-59, doi: 10.1111/j.1524-4725.2007.34008.x, indexed in Pubmed: 18053050.

46. Sattler G, Callander MJ, Grablowitz D, et al. Noninferiority of incobotulinumtoxinA, free from complexing proteins, compared with another botulinum toxin type A in the treatment of glabellar frown lines. Dermatol Surg. 2010; 36 Suppl 4: 2146-2154, doi: 10.1111/j.1524-4725.2010.01706.x, indexed in Pubmed: 21134045.

47. Carli L, Montecucco C, Rossetto O. Assay of diffusion of different botulinum neurotoxin type a formulations injected in the mouse leg. Muscle Nerve. 2009; 40(3): 374-380, doi: 10.1002/mus.21343, indexed in Pubmed: 19618426.

48. Brodsky MA, Swope DM, Grimes D. Diffusion of botulinum toxins. Tremor Other Hyperkinet Mov (N Y). 2012; 2, doi: 10.7916/ D88W3C1M, indexed in Pubmed: 23440162.

49. Girlanda P, Vita G, Nicolosi C, et al. Botulinum toxin therapy: distant effects on neuromuscular transmission and autonomic nervous system. J Neurol Neurosurg Psychiatry. 1992; 55(9): 844-845, doi: 10.1136/jnnp.55.9.844, indexed in Pubmed: 1328540.

50. Caleo M, Spinelli M, Colosimo F, et al. Transynaptic Action of Botulinum Neurotoxin Type A at Central Cholinergic Boutons. J Neurosci. 2018; 38(48): 10329-10337, doi: 10.1523/JNEUROSCl.0294-18.2018, indexed in Pubmed: 30315128.

51. Antonucci F, Rossi C, Gianfranceschi L, et al. Long-distance retrograde effects of botulinum neurotoxin A. J Neurosci. 2008; 28(14): 3689-3696, doi: 10.1523/JNEUROSCI.0375-08.2008, indexed in Pubmed: 18385327.

52. Restani L, Antonucci F, Gianfranceschi L, et al. Evidence for anterograde transport and transcytosis of botulinum neurotoxin A (BoNT/A). J Neurosci. 2011; 31(44): 15650-15659, doi: 10.1523/JNEUROSCl.2618-11.2011, indexed in Pubmed: 22049408.

53. Restani L, Novelli E, Bottari D, et al. Botulinum neurotoxin A impairs neurotransmission following retrograde transynaptic transport. Traffic. 2012; 13(8): 1083-1089, doi: 10.1111/j.1600-0854.2012.01369.x, indexed in Pubmed: 22519601.

54. Wang T, Martin S, Papadopulos A, et al. Control of autophagosome axonal retrograde flux by presynaptic activity unveiled using bo- 
tulinum neurotoxin type a. J Neurosci. 2015; 35(15): 6179-6194, doi: 10.1523/JNEUROSCI.3757-14.2015, indexed in Pubmed: 25878289.

55. Maday S, Holzbaur ELF. Autophagosome assembly and cargo capture in the distal axon. Autophagy. 2012; 8(5): 858-860, doi: 10.4161/ auto.20055, indexed in Pubmed: 22617438.

56. Harper CB, Martin S, Nguyen TH, et al. Dynamin inhibition blocks botulinum neurotoxin type $A$ endocytosis in neurons and delays botulism. J Biol Chem. 2011; 286(41): 35966-35976, doi: 10.1074/jbc. M111.283879, indexed in Pubmed: 21832053.

57. Restani L, Giribaldi F, Manich M, et al. Botulinum neurotoxins A and E undergo retrograde axonal transport in primary motor neurons. PLoS Pathog. 2012; 8(12): e1003087, doi: 10.1371/journal. ppat.1003087, indexed in Pubmed: 23300443.

58. Barbanti P, Ferroni P. Onabotulinum toxin A in the treatment of chronic migraine: patient selection and special considerations. J Pain Res. 2017; 10: 2319-2329, doi: 10.2147/JPR.S113614, indexed in Pubmed: 29033605.

59. Simpson L. The life history of a botulinum toxin molecule. Toxicon. 2013; 68: 40-59, doi: 10.1016/j.toxicon.2013.02.014, indexed in Pubmed: 23518040.

60. Joshi SG, Elias M, Singh A, et al. Modulation of botulinum toxin-induced changes in neuromuscular function with antibodies directed against recombinant polypeptides or fragments. Neuroscience. 2011; 179: 208-222, doi: 10.1016/j.neuroscience.2011.01.033, indexed in Pubmed: 21277940.

61. Chen F, Kuziemko GM, Amersdorfer P, et al. Antibody mapping to domains of botulinum neurotoxin serotype $A$ in the complexed and uncomplexed forms. Infect Immun. 1997; 65(5): 1626-1630, doi: 10.1128/IAI.65.5.1626-1630.1997, indexed in Pubmed: 9125539 .

62. ВОТОХ $®$ (onabotulinumtoxinA) [prescribing information]. Irvine, СА: Allergan, Inc.; 2013. , Accessed October. ; 8: 2020.

63. Brin MF, Comella CL, Jankovic J, et al. CD-017 BoNTA Study Group. Long-term treatment with botulinum toxin type A in cervical dystonia has low immunogenicity by mouse protection assay. Mov Disord. 2008; 23(10): 1353-1360, doi: 10.1002/mds.22157, indexed in Pubmed: 18546321.

64. FDA Approval Package for Xeomin $®$ (incobotulinumtoxinA) Injection. vol Application Number 125360 [webpage on the Internet] Silver Spring, MD: US Food and Drug Administration; 2010. Available from: http://www.accessdata.fda.gov/drugsatfda_docs/ nda/2010/125360s0000TOC.cfm. Accessed October. 2010; 8: 2020.

65. Fabbri M, Leodori G, Fernandes RM, et al. Neutralizing Antibody and Botulinum Toxin Therapy: A Systematic Review and Meta-analysis. Neurotox Res. 2016; 29(1): 105-117, doi: 10.1007/s12640-0159565-5, indexed in Pubmed: 26467676.

66. Wissel J, Bensmail D, Ferreira JJ, et al. TOWER study investigators. Safety and efficacy of incobotulinumtoxinA doses up to $800 \mathrm{U}$ in limb spasticity: The TOWER study. Neurology. 2017; 88(14): 1321-1328, doi: 10.1212/WNL.0000000000003789, indexed in Pubmed: 28283596.

67. Naumann M, Dressler D, Hallett M, et al. Evidence-based review and assessment of botulinum neurotoxin for the treatment of secretory disorders. Toxicon. 2013; 67: 141-152, doi: 10.1016/j.toxicon.2012.10.020, indexed in Pubmed: 23178324.

68. Jost WH, Benecke R, Hauschke D, et al. Clinical and pharmacological properties of incobotulinumtoxinA and its use in neurological disor- ders. Drug Des Devel Ther. 2015; 9: 1913-1926, doi: 10.2147/ DDDT.S79193, indexed in Pubmed: 25897202.

69. Schantz E, Johnson E. Dose standardisation of botulinum toxin. The Lancet. 1990; 335(8686): 421, doi: 10.1016/01406736(90)90263-5.

70. Sesardic T. Bioassays for evaluation of medical products derived from bacterial toxins. Curr Opin Microbiol. 2012; 15(3): 310-316, doi: 10.1016/j.mib.2012.05.008, indexed in Pubmed: 22651974.

71. Hunt T, Clarke K. Potency evaluation of a formulated drug product containing 150-kd botulinum neurotoxin type A. Clin Neuropharmacol. 2009; 32(1): 28-31, doi: 10.1097/WNF.0B013E3181692735, indexed in Pubmed: 18978494.

72. Panjwani N, O'Keeffe R, Pickett A. Biochemical, functional and potency characteristics of type A botulinum toxin in clinical use. The Botulinum J. 2008; 1(1): 153, doi: 10.1504/tbj.2008.018956.

73. Dressler $D$, Mander G, Fink K. Measuring the potency labelling of onabotulinumtoxinA (Botox $(\circledR))$ and incobotulinumtoxinA (Xeomin $(\circledR))$ in an LD50 assay. J Neural Transm (Vienna). 2012; 119(1): 13-15, doi: 10.1007/s00702-011-0719-1, indexed in Pubmed: 21971766.

74. Sesardic D, Leung T, Gaines Das R. Role for standards in assays of botulinum toxins: international collaborative study of three preparations of botulinum type A toxin. Biologicals. 2003; 31(4): 265-276, doi: 10.1016/j. biologicals.2003.08.001, indexed in Pubmed: 14624797.

75. Dashtipour K, Pedouim F. Botulinum Toxin: Preparations for Clinical Use, Immunogenicity, Side Effects, and Safety Profile. Semin Neurol. 2016; 36(1): 29-33, doi: 10.1055/s-0035-1571213, indexed in Pubmed: 26866493.

76. Scaglione F. Conversion Ratio between Botox $\AA^{\circledR}$, Dysport ${ }^{\circledR}$, and Xeo$\min \circledast$ in Clinical Practice. Toxins (Basel). 2016; 8(3), doi: 10.3390/ toxins8030065, indexed in Pubmed: 26959061.

77. Rosales RL, Bigalke H, Dressler D. Pharmacology of botulinum toxin: differences between type A preparations. Eur J Neurol. 2006; $13 \mathrm{Su}$ ppl 1: 2-10, doi: 10.1111/j.1468-1331.2006.01438.x, indexed in Pubmed: 16417591.

78. Brown M, Nicholson G, Ardila MC, et al. Comparative evaluation of the potency and antigenicity of two distinct BoNT/A-derived formulations. J Neural Transm (Vienna). 2013; 120(2): 291-298, doi: 10.1007/ s00702-012-0854-3, indexed in Pubmed: 22842675.

79. Hunt T, Clarke K, Rupp D, et al. IncobotulinumtoxinA drug product demonstrates lower potency when compared to onabotulinumtoxinA drug product with concurrent lower light-chain activity and atypical substrate cleavage. Toxicon. 2013; 68: 114, doi: 10.1016/j.toxicon.2012.07.147.

80. Ferrari A, Manca M, Tugnoli V, et al. Pharmacological differences and clinical implications of various botulinum toxin preparations: a critical appraisal. Funct Neurol. 2018; 33(1): 7-18, doi: 10.11138/ fneur/2018.33.1.007, indexed in Pubmed: 29633692.

81. Field M, Splevins A, Picaut $P$, et al. AbobotulinumtoxinA (Dysport), OnabotulinumtoxinA (Botox), and IncobotulinumtoxinA (Xeomin) Neurotoxin Content and Potential Implications for Duration of Response in Patients. Toxins (Basel). 2018; 10(12), doi: 10.3390/ toxins10120535, indexed in Pubmed: 30551641.

82. Allergan, Ltd. ВОTOХ® 100 U. Summary of product characteristics [webpage on the Internet]. Surrey, UK: Datapharm Communications Ltd; 2013 [updated December 12, 2012]. Available from: http://www. medicines.org.uk/emc/medicine/112. Accessed October. ; 8: 2020.

83. ВОTOX® (onabotulinumtoxinA) [prescribing information]. Buenos Aires, Argentina: Allergan, Inc. ; 2011. 